
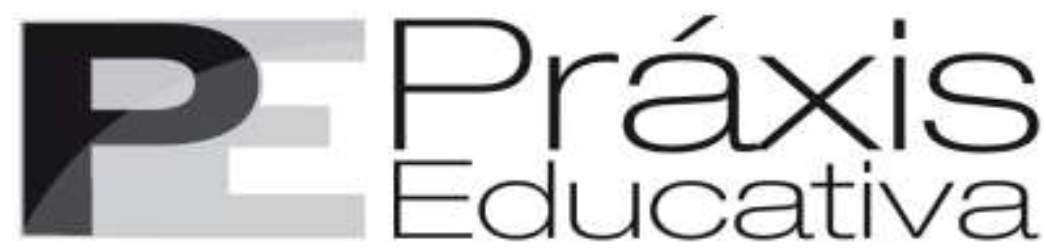

ISSN 1809-4031

eISSN 1809-4309

https://doi.org/10.5212/PraxEduc.v.17.19336.033

Dossiê: Relações étnico-raciais: práticas e reflexões pedagógicas em contextos, espaços e tempos

\title{
Educação em saúde da população negra na Estratégia Saúde da Família
}

\section{Health education of the black population in the Family Health Strategy}

Educación en salud de la población negra en la Estrategia Salud de la Familia

\author{
Adicéa de Souza Ferreira* \\ iD https://orcid.org/0000-0002-4977-3835
}

Resumo: O presente artigo tem como proposta contextualizar a educação em saúde da população negra na Estratégia Saúde da Família quanto aos seus limites e às suas possibilidades. Visto que essa população se constrói e se reconstrói perante a sociedade, na qual o racismo predomina de uma forma marcante, em que existem territórios nos quais vidas negras acontecem, desde a escravidão e mesmo com a abolição da escravatura, o racismo prevalece. Contudo, surgiram alguns movimentos de lutas a favor da igualdade e das políticas de saúde que colaboram para a equidade da população negra. A educação em saúde dentro da Estratégia Saúde da Família contribui para o autocuidado da população negra que, na maioria das vezes, se encontra invisivel.

Palavras-chave: Estratégia Saúde da Família. Educação em saúde. População negra. Racismo.

Abstract: This article proposes to contextualize health education for the black population in the Family Health Strategy in terms of its limits and its possibilities. Since this population is built and rebuilt in the face of society, in which racism predominates in a marked way, where there are territories in which black lives take place, since slavery and even with the prevailing abolition of slavery, racism prevails. However, some movements of struggles in favor of equality and health policies that collaborate for the equity of the black population have emerged. Health education within the Family Health Strategy contributes to the self-care of the black population, which in most cases is invisible.

Keywords: Family Health Strategy. Health education. Black population. Racism.

Resumen: El presente artículo tiene como propuesta contextualizar la educación en salud de la población negra en la Estrategia Salud de la Familia en lo que se refiere a sus límites y a sus posibilidades. Ya que esta población se construye y reconstruye frente a la sociedad, en la que el racismo predomina de forma marcada, donde existen territorios en los que vidas negras ocurren, desde la esclavitud y aun con la abolición de la

\footnotetext{
* Enfermeira. Doutoranda no Programa de Pós-Graduação em Bioética, Ética Aplicada e Saúde Coletiva (PPGBIOS) da Universidade Federal do Rio de Janeiro (UFRJ). Mestre em Educação em Saúde: Formação Interdisciplinar de Docentes pelo Sistema Único de Saúde (SUS) pela Escola de Enfermagem Aurora de Afonso Costa da Universidade Federal Fluminense (UFF). Membro do Núcleo de Estudos e Pesquisas em Gestão e Trabalho em Saúde (NUPGESUFF). Membro do Núcleo de Pesquisa Laboratório de Experimentos Artísticos e Reflexões Criativas sobre Cidades, Saúde e Educação (LEARCC) da Universidade do Estado do Rio de Janeiro (UERJ). E-mail: <adiceafer@gmail.com>.
}

Práxis Educativa, Ponta Grossa, v. 17, e2219336, p. 1-10, 2022 Disponível em: < https://revistas2.uepg.br/index.php/praxiseducativa> 
esclavitud, prevalece el racismo. Sin embargo, han surgido algunos movimientos de luchas a favor de la igualdad y de las políticas de salud que colaboran por la equidad de la población negra. La educación en salud dentro de la Estrategia Salud de la Familia contribuye al autocuidado de la población negra, que en la mayoría de los casos se encuentra invisible.

Palabras clave: Estrategia Salud de la Familia. Educación en salud. Población Negra. Racism.

\section{Introdução}

O conceito de "educação em saúde", de acordo com os Descritores em Ciências da Saúde/Medical Subject Headings (DeCS/MeSH), objetiva desenvolver nas pessoas um sentido de responsabilidade como indivíduo, membro de uma família e de uma comunidade com a saúde, tanto individual como coletivamente (DECS, 2020).

A educação em saúde, no Brasil, teve seu primeiro momento no final do século XIX e início do século XX, em virtude das necessidades de domínio sobre epidemias de varíola, de peste, de febre amarela, de tuberculose, entre outras doenças infectocontagiosas da época. Desse modo, as ações educativas restringiam-se às questões de higiene e de conscientização sanitária abrangentes (GONDRA, 2000).

Nesse sentido, a educação em saúde, como prática de medidas educativas ou preventivas quanto à promoção da saúde dos sujeitos, tem se desenvolvido na Estratégia Saúde da Família (ESF) proposta pelo Ministério da Saúde em 1994, que incorpora e reafirma os princípios do Sistema Único de Saúde (SUS) e está estruturada com ênfase na Atenção Básica à Saúde, em especial da Saúde da Família (ALVES; AERTS, 2011).

A ESF objetiva a reorganização e a estruturação da Atenção Básica e configura o primeiro acesso do indivíduo à saúde, quer dizer, o primeiro contato com a unidade de saúde, em que a maior parte dessas pessoas são negras e negros das periferias urbanas, onde as práticas ou as ações de saúde acontecem. De acordo com o Censo de 2010, do Instituto Brasileiro de Geografia e Estatística - IBGE (2010), negras e negros constituem mais da metade da população brasileira (50,7\%). Assim, visando a promoção e a garantia da equidade em saúde para a população negra, instituiu-se a Política Nacional de Saúde Integral da População Negra (PNSIPN), por meio da Portaria $\mathrm{N}^{\circ}$ 992, de 13 de maio de 2009, desdobrando-se sobre as desigualdades com as quais esse segmento populacional se encontra ligado frequentemente, assegurando a promoção da igualdade racial e a efetivação da equidade e do acesso ao direito à saúde, enfocando todos os aspectos que envolvem a PNSIPN ${ }^{1}$ (BRASIL, 2009, 2017).

Segundo Sen (2002), a equidade em saúde tem múltiplas facetas e o melhor é vê-la como um conceito multidimensional que inclui aspectos relacionados ao nível de saúde que se tem e à possibilidade de se obtê-la, e não apenas com a distribuição do cuidado sanitário. Ela inclui a justiça dos processos e, por conseguinte, deve atentar-se à ausência de discriminações na prestação da assistência. Ademais, um bom compromisso com a equidade em saúde necessita, também, que as considerações sobre a saúde sejam integradas. Assim sendo, dentre as múltiplas faces, a população negra encontra-se habitada no território da ESF, no qual a educação em saúde se faz presente no sentido da construção das ações em saúde.

\footnotetext{
1 A PNSIPN tem possibilitado que a temática racial seja pautada para a promoção da equidade em saúde. O marco dessa política é o reconhecimento do racismo, das desigualdades étnico-raciais e do racismo institucional como determinantes sociais das condições de saúde (CANAVESE et al., 2018).
}

Práxis Educativa, Ponta Grossa, v. 17, e2219336, p. 1-10, 2022 


\title{
Educação em saúde e a caminhada da população negra
}

O termo "educação em saúde" vem sendo utilizado desde as primeiras décadas do século XX e para melhor compreensão sua se faz necessário o entendimento da história da saúde pública no Brasil. A expansão da medicina preventiva para algumas regiões do país deu-se a partir da década de 1940, com o Serviço Especial de Saúde Pública (Sesp), o qual apresentava estratégias de educação em saúde autoritárias, tecnicistas e biologicistas, em que as classes vulneráveis, incluindo a população negra, eram vistas e tratadas como passivas e incapazes de iniciativas próprias (VASCONCELLOS, 2001).

Hoje, o cenário da ESF divide-se em territórios em que a vida acontece. A educação em saúde constitui-se como conjunto de atividades em prol de melhorias da qualidade de vida e de ações de saúde dos indivíduos, incluindo a população negra, em que há necessidade de intervenções comunitárias no habitat na ESF. Segundo o documento Glossário temático: gestão do trabalho e da educação na saúde (BRASIL, 2012), define-se educação em saúde como:

\begin{abstract}
Processo educativo de construção de conhecimentos em saúde que visa à apropriação temática pela população [...]. Conjunto de práticas do setor que contribui para aumentar a autonomia das pessoas no seu cuidado e no debate com os profissionais e os gestores a fim de alcançar uma atenção de saúde de acordo com suas necessidades. (BRASIL, 2012, p. 19-20).
\end{abstract}

A partir dessa definição, compreende-se a autonomia do sujeito, corresponsabilizando os profissionais e os gestores de saúde, e o conjunto de práticas, no que diz respeito às ações de saúde territoriais, visando constituir propostas positivas e reflexões críticas às mudanças do eixo saúde da população negra adstrita na ESF. Para tal situação, precisa-se da educação em saúde como processo construtivo da realidade habitacional, levando em consideração a estrutura, a cultura e o diagnóstico situacional da localidade em que a população negra se encontra.

A educação em saúde é um subsídio eficaz para que as pessoas desenvolvam juízo crítico e capacidade de intervenção sobre suas vidas e sobre o ambiente com o qual interagem para, assim, criarem condições para se apropriarem de sua própria existência. Desse modo, ela não deve ser exclusiva ou limitante, no que se refere à formação de grupos mistos ou de novos grupos de interesse geral (ARAÚJO; DIAS; BUSTORFF, 2011).

As ações de educação em saúde remetem ao incentivo dos usuários em vários sentidos, como a introdução na sua vida diária de uma nova postura frente ao autocuidado, promovendo melhoras bastante significativas no tocante à qualidade de vida e à adaptação da vida em coletividade, bem como à relação com seus familiares e/ou cuidadores, os quais mantêm vínculos diários, sempre se articulando com a ESF como processo singular para a efetivação dessas práticas (DIAS; SILVEIRA; WITT, 2009).

A educação em saúde como transmissão de informações, nos diferentes sentidos, se traduz por levar até à população negra compreensão e soluções consideradas corretas pelos profissionais, não valorizando as diferentes formas de apreensão do conhecimento e a possibilidade de recriá-lo, de acordo com valores, crenças e cultura de cada indivíduo ou grupo. Dessa forma, a educação em saúde acaba se tornando uma atividade saturada, em que os objetivos não são alcançados como desejado (SILVA et al., 2017).

Outra ideia vinculada à educação em saúde é que esta serve de ferramenta de indução para a mudança nos comportamentos de risco dos indivíduos e da comunidade. Tal percepção favorece o modelo de educação em saúde mais tradicional, o qual acredita que a educação em saúde baseada

Práxis Educativa, Ponta Grossa, v. 17, e2219336, p. 1-10, 2022 Disponível em: <https:// revistas2.uepg.br/index.php/praxiseducativa> 
no repasse de informações pode provocar a adoção de comportamentos ditos saudáveis (SILVA et al., 2017).

Os campos de ação da promoção da saúde estão atrelados ao desenvolvimento de atitudes e de habilidades pessoais que favoreçam a saúde. Dessa maneira, é imprescindível a divulgação de informações sobre a educação para a saúde em todos os ambientes da sociedade, uma vez que essas ações podem ser concretizadas em diversos espaços e instituições sociais (CASARIN; PICOLLI, 2011).

Essa caminhada da população negra relaciona-se com a educação em saúde, a qual abrange os sujeitos em todas as fases da vida - a gestante, a criança, o adolescente, o jovem, o adulto-jovem, o adulto e o idoso de ambos os sexos e gêneros -, uma vez que as ações de educação em saúde auxiliam a redução quanto ao risco de várias doenças, compreendendo as doenças crônicas não transmissíveis e as doenças infectocontagiosas, que se encontrão presentes no cotidiano do século XXI. Assim sendo, a educação em saúde é um dispositivo que opera como ferramenta nas ações em saúde no âmbito da ESF e deve ser considerada como processo de conscientização individual e coletiva, envolvendo a equidade da população negra no planejamento organizacional das ações em saúde, estimulando intervenções práticas no campo do SUS.

\section{A política da população negra perante a desigualdade social e o racismo}

O racismo diz respeito a todo fenômeno fundamentado no conceito de raça e de cor que promova distinções, preferências, exclusões e restrições entre os sujeitos em qualquer domínio da vida. $\mathrm{Na}$ região brasileira, características fenotípicas vinculadas à ideia de raça (como a cor da pele, o formato dos lábios e do nariz, a textura e a forma do cabelo) são atributos utilizados para diferenciar e para hierarquizar os grupos raciais. Essas características acabam, portanto, levando a população negra a uma situação de exclusão e de vulnerabilidade, tanto social quanto do acesso à saúde, limitando oportunidades e expectativa de vida² (BRASIL, 1969).

Em 2006, o Ministério da Saúde reconheceu o conceito de racismo institucional e, no ano de 2009, foi lançada a PNSIPN, cuja marca é “[...] o reconhecimento do racismo, das desigualdades étnico-raciais e do racismo institucional como determinantes sociais e condições de saúde, com vistas à promoção de equidade em saúde" (BRASIL, 2009, n.p.). A instituição dessa Política é o marco de uma longa caminhada, na qual os movimentos sociais foram fundamentais (MATOS; TOURINHO, 2018).

O racismo institucional está diretamente ligado à forma como a sociedade está estruturada e à falta de reconhecimento da cidadania plena da população negra, resultando uma redução do acesso integral a bens e a serviços de qualidade, menor participação e negligência das necessidades específicas e potencializando agravos à saúde. As práticas discriminatórias oriundas do racismo são eventos que emergem em vários âmbitos: nas relações interpessoais, na família, na distribuição geográfica dos espaços urbanos, na formação de círculos sociais e mesmo nas instituições, dificultando e, muitas vezes, impedindo o acesso a um serviço de saúde de qualidade (BRASIL, 2016).

\footnotetext{
2 "No Brasil, o racismo tem suas raízes na escravidão e, por conseguinte, na 'anulação dos valores da cultura negra feita pelos colonizadores como forma de legitimar a dominação' [...]. A força desse racismo pode ser medida pelo fato de a escravidão ter dominado a história do Brasil por mais de três séculos, sendo o último país do mundo a aboli-la. [...], 'Nenhuma outra região do Novo Mundo foi tão completamente modelada e condicionada pela escravidão quanto o Brasil. Simplesmente, a escravidão fez o Brasil"” (KALCKMANN et al., 2007, p. 148).
}

Práxis Educativa, Ponta Grossa, v. 17, e2219336, p. 1-10, 2022 Disponível em: <https://revistas2.uepg.br/index.php/praxiseducativa $>$ 
O racismo institucional afeta muitas dimensões de sua existência, provocando situações de opressão, de exclusão, de discriminação socioeconômica, o que coloca a população negra em uma situação de maior vulnerabilidade diante de uma série de agravos que contribuem para o comprometimento da saúde. Essas desigualdades refletem nos dados epidemiológicos que evidenciam a diminuição da qualidade e da expectativa de vida da população negra, devido as altas taxas de morte materna e infantil por causas externas, como diabetes, câncer no colo do útero, dentre outras (BRASIL, 2017). Segundo Sampaio (2003), com base no relatório de inquérito sobre o assassinato de um jovem negro, em 1993, por um grupo racista branco, o racismo institucional é definido como o

[...] fracasso coletivo de uma organização para prover um serviço apropriado e profissional para as pessoas por causa de sua cor, cultura ou origem étnica. Ele pode ser visto ou detectado em processos, atitudes e comportamentos que totalizam em discriminação por preconceito involuntário, ignorância, negligência e estereotipação racista, que causa desvantagens a pessoas de minoria étnica. (SAMPAIO, 2003, p. 82, tradução do autor).

O racismo institucional, na prática da ESF, pode ser entendido quando um usuário negro entra na unidade para obter informações de como iniciar seu tratamento ou acompanhamento, e o profissional tende a negar-lhe a informação ou dar-lhe a informação incorreta; dessa forma, essa pessoa negra não entende o que lhe foi dito e, assim, não obtém seu tratamento. Outra situação relevante é quando uma pessoa negra sente um mal-estar e não é ouvida ou atendida nos serviços de saúde, uma vez que alguns profissionais acreditam que ela, por ser negra, é tolerante à dor.

A conduta desses profissionais tem de ser mudada, visto que o negro também é feito de carne e osso, sente dores, tem sangramentos, tem um corpo na carne que tem de ser compreendido. A PNSIPN foi implementada para que profissionais de saúde, gestores de saúde, a sociedade em geral, entre outras instâncias, tratem a população negra igual a outras nações de pele não negra.

A forma de adoecimento e de morte da população negra é decorrente do processo histórico da escravidão ocorrido no Brasil, em que o acesso à saúde e à educação não chegavam a essa população, pois os trabalhos escravos acometidos eram intensos. O racismo, na época da escravatura, foi marcante, dado que a cor da pele é um fato trazido na memória até os dias de hoje.

A população negra, em nosso país, em sua grande maioria, concentra-se em periferias, favelas e comunidades dos grandes centros urbanos, convivendo com a falta de saneamento básico, que favorece para a propagação de doenças; com a violência, que contribui para alterações da saúde mental; com o uso de drogas e o consumo de álcool, que também podem se relacionar com a saúde mental, entre outros fatores relevantes. A educação em saúde, quando implementada à saúde da população negra, propicia a diminuição das desigualdades sociais e a possível exclusão do racismo no ambiente de saúde e na sociedade.

\section{O Movimento Negro como espaço para a educação em saúde}

$\mathrm{Na}$ década de 1980, durante o processo de abertura política e de redemocratização da sociedade, assistiu-se a uma nova forma de atuação política dos negros (e negras) brasileiros. Estes passaram a atuar ativamente por meio dos novos movimentos sociais, sobretudo os de caráter identitário, trazendo outro conjunto de problematização e novas formas de atuação e de reivindicação política. Assim, o Movimento Negro indaga a exclusividade do enfoque sobre a classe social presente nas denúncias da luta dos movimentos sociais da época. As suas reivindicações assumem caráter muito mais profundo: indagam o Estado, os movimentos sociais sobre o seu

Práxis Educativa, Ponta Grossa, v. 17, e2219336, p. 1-10, 2022

Disponível em: <https://revistas2.uepg.br/index.php/praxiseducativa $>$ 
posicionamento neutro e omisso diante da centralidade da raça na formação do país (GOMES, 2011).

Nas ações e nas lutas desenvolvidas pela população negra nos séculos XIX, XX e no começo do século XXI, uma questão sempre atraiu a sua atenção graças ao seu papel estratégico na sociedade: a educação. Esta se tornou uma forte bandeira de luta do Movimento Negro no século XX. Os ativistas do Movimento Negro reconhecem que a educação não é a solução de todos os males, porém ocupa lugar importante nos processos de produção de conhecimento sobre si e sobre "os outros", contribui para a formação de quadros intelectuais e políticos e é constantemente usada pelo mercado de trabalho como critério de seleção de uns e de exclusão de outros (GOMES, 2011).

No entanto, a educação mencionada por Gomes (2011) configura-se como um espaço intercessor para a educação em saúde da ou para a população negra. Embora ela não seja a solução, pode ser um elemento condicional de transformação de inclusão do negro não somente no mercado de trabalho, mas também na sociedade ou na comunidade.

Um dos resultados da Constituição Federal de 1988 (BRASIL, 1988) foi materializado pela Carta Magna: o estabelecimento das bases legais para a construção de um sistema de saúde único, de caráter universalista, igualitário e de promoção do Estado. A década de 1990 foi o estopim reivindicatório de políticas de superação ao racismo pelo Movimento Negro. Repertórios de ação foram mobilizados, tais como a Marcha Zumbi Contra o Racismo, pela Cidadania e pela Vida, que levou o Estado a criar o Grupo Interministerial para Valorização da População Negra. Assim, o movimento caminhou da mobilização de rua para a mobilização institucional (FERREIRA, 2017).

As primeiras movimentações que abordaram a temática da saúde datam da década de 1980, em que foi marcante a militância das mulheres negras. Elas, na época, discutiram direitos sexuais e reprodutivos, gerando dados sobre desigualdades raciais e levantando a importância do recorte racial na saúde. Logo, teve-se a Constituição Federal, a qual teve importante participação de diferentes organizações do Movimento Negro (FERREIRA, 2017).

Ao longo da história brasileira, condições desiguais foram geradas para determinados segmentos da população com características étnicas e sociais específicas, resultando um quadro de iniquidades enfrentado por esses segmentos e, no que se refere à população negra, em um racismo que, mesmo após a abolição oficial da exploração dos povos africanos em território nacional, persistiu silencioso, não declarado e, muitas vezes, silenciado (BRASIL, 2016).

Com o silêncio desses povos silenciados, sua identidade é definida como forma altamente reflexiva, formada por fenômenos inconscientes e pelo imaginário. Está sempre "em movimento", sempre "sendo formada", constituindo-se em um processo histórico. Assim, diante das múltiplas e das variadas identidades, o sujeito constitui sua própria identidade social, na medida em que interage em situações, instituições ou agrupamentos sociais, o que ocasiona um sentido de pertencimento a um grupo social de referência. Identidade, como conceito polissêmico, pode representar o que o sujeito tem de mais peculiar e, ao mesmo tempo, pode apontar o pertencimento ao mesmo grupo (AZEVEDO; OLIVEIRA, 2017).

A identidade aqui referida afeta a população negra no sentido de sua existência na sociedade, pois sua representatividade em um grupo está em constante movimento. Por sua vez, esse movimento se compreende na história da população negra que, até hoje, no ano de 2021, ainda se faz presente quanto à polissemia da identidade. A liberdade chegou em 13 de maio de 1888, mas, mesmo assim, continua-se em cárcere por algumas pessoas da sociedade que cultivam o racismo e

Práxis Educativa, Ponta Grossa, v. 17, e2219336, p. 1-10, 2022 Disponível em: < https://revistas2.uepg.br/index.php/praxiseducativa> 
privam a população negra de liberdade. As pessoas têm o direito de uma educação em saúde, de cuidado do corpo, mas como, se isso é privado a elas?

\section{Discussão}

Um estudo de 2017 revela o impacto da ESF sobre a redução da mortalidade por causas evitáveis na população negra após 13 anos de implantação desse programa: redução de 27,5\% na mortalidade por doenças infecciosas e de 19,3\% de diabetes na população negra, além de diminuição de 17,9\% nas mortes por deficiências nutricionais e anemia nas crianças menores de cinco anos, o que sugere o papel essencial da ESF no cuidado integral e na concretização da real equidade em saúde (HONE et al., 2017).

A educação em saúde deve constituir parte essencial na promoção da saúde, na prevenção de doenças, como também contribuir para o tratamento precoce e eficaz das doenças, minimizando o sofrimento e a incapacidade. A ação educativa, na atenção primária, estabelece-se a partir de programas determinados verticalmente ou ligados às ações de promoção da saúde e de prevenção da doença junto à comunidade, aos indivíduos ou aos grupos sociais, permeando densamente uma participação ativa do sujeito, possibilitando a transformação de suas atitudes, de seus conhecimentos e de suas habilidades para lidar com os problemas de saúde (DIAS; SILVEIRA; WITT, 2009).

Dessarte, a saúde da população negra tem sido objeto de políticas no Brasil, pois possui características que conferem disparidades no que diz respeito às condições de saúde, seja do ponto de vista individual ou coletivo. A fim de promover a equidade, no que se refere à efetivação do direito humano à saúde dessa população, o Conselho Nacional de Saúde (CNS) aprovou, no dia 10 de novembro de 2006, a PNSIPN, que tem como objetivo a promoção da equidade em saúde, em função de situações de risco, com vistas ao maior cuidado com a saúde da população negra, emergindo como uma ferramenta importante na reestruturação da saúde por meio de uma política que adere à demanda e à realidade do país (BRASIL, 2017).

Estudos importantes sobre a situação de saúde da população negra no Brasil e seus determinantes sociais foram imprescindíveis para nortear as estratégias de ação prioritária da PNSIPN. Destacam-se as pesquisas realizadas pelo IBGE e pelo Instituto de Pesquisa Econômica Aplicada (Ipea) nos idos dos anos 2000, proporcionando dados sobre os baixos níveis de renda desse segmento, tanto no nível individual como domiciliar per capita, como fator limitante das liberdades individuais e sociais dos sujeitos (BRASIL, 2005).

Além disso, contou-se com a importante contribuição do Relatório Saúde Brasil publicado em 2005, que trouxe uma análise minuciosa segundo raça, cor e etnia, que permitiu constatar o quanto a população negra deste país estava mais vulnerável aos agravos, ao adoecimento e à morte quando comparada com a população branca, devido às condições desfavoráveis a que estava submetida (BRASIL, 2005).

É importante contextualizar o relatório de saúde brasileiro no sentido ampliado das mudanças relacionadas às ações de saúde para a população negra que se encontra vulnerável, quanto aos construtos desenvolvidos em comparação com outras etnias e pessoas de pele não negra. A educação em saúde aqui exposta denota a intensidade estrutural descrita por alguns autores determinantes e condicionantes em saúde, o enfrentamento do racismo e da desigualdade social. As características socioeconômicas e sociodemográficas são fatores contributivos para o processo de morbimortalidade da população negra; é necessário, portanto, compreender que a equidade

Práxis Educativa, Ponta Grossa, v. 17, e2219336, p. 1-10, 2022 
como necessidade de romper barreiras estruturadas por indivíduos na sociedade se reduz com a educação em saúde.

\section{Considerações finais}

Os limites e as possibilidades em que a população negra se encontra condiz com a atual conjuntura de reflexões e de críticas relacionadas à educação em saúde em seus territórios. A vulnerabilidade, ou seja, a fragilidade para com a população negra está em luta, uma luta com avanços positivos evidenciados a essa população que, por conta da sua cor da pele "escurecida", convive com a exclusão.

Desde 1969, discute-se o racismo e a limitação quanto ao acesso à saúde. Em 1980, com o surgimento de alguns movimentos negros, o processo de mitigação foi se rompendo e a população negra foi ganhando espaço na sociedade. Contudo, as políticas da população negra foram implementadas tardiamente, o que corrobora os limites e as possibilidades em que os negros se encontram no ano de 2021. Assim sendo, espera-se, com este estudo, provocar inquietação no que diz respeito à educação em saúde para a população negra, visto que a educação em saúde visa a colaborar com a equidade e o autocuidado em saúde onde essa população reside.

\section{Referências}

ALVES, G. G.; AERTS, D. As práticas educativas em saúde e a Estratégia Saúde da Família. Ciência \& Saúde Coletiva, Rio de Janeiro, v. 16, n. 1, p. 319-325, jan. 2011. DOI: https://doi.org/10.1590/S1413-81232011000100034

ARAÚJO, V. S.; DIAS, M. D.; BUSTORFF, L. A. C. V. A instrumentalização da educação em saúde na atenção básica. Revista de Enfermagem, Coimbra, v. 5, n. 4, p. 7-17, dez. 2011. DOI: http://dx.doi.org/10.12707/RIII1143

AZEVEDO, A. D. M.; OLIVEIRA, I. A. O racismo no contexto educativo: uma questão ética e de direitos humanos. Revista Eletrônica de Educação, São Carlos, v. 11, n. 2, p. 626-636, jun./ago. 2017. DOI: http://dx.doi.org/10.14244/198271992185

BRASIL. Decreto $\mathbf{N}^{\mathbf{0}} \mathbf{6 5 . 8 1 0}$, de 8 de dezembro de 1969. Promulga a Convenção Internacional sobre a Eliminação de todas as Formas de Discriminação Racial. Brasilia: Presidência da República, Casa Civil, Subchefia de Assuntos Jurídicos, [1969]. Disponível em: http://www.planalto.gov.br/ccivil_03/decreto/1950-1969/D65810.html. Acesso em: 17 fev. 2022.

BRASIL. [Constituição (1988)]. Constituição da República Federativa do Brasil. Brasília, DF: Senado, 1988.

BRASIL. Saúde Brasil 2005: uma análise da situação de saúde no Brasil. Brasília: Ministério da Saúde, Secretaria de Vigilância em Saúde, Departamento de Análise de Situação em Saúde, 2005. Disponível em: http://bvsms.saude.gov.br/bvs/publicacoes/saude_brasil_2005parte1.pdf. Acesso em: 17 fev. 2022.

BRASIL. Portaria No 992, de 13 de maio de 2009. Institui a Política Nacional de Saúde Integral da População Negra. Brasília: Ministério da Saúde, Gabinete do Ministro, [2009]. Disponível em: https://bvsms.saude.gov.br/bvs/saudelegis/gm/2009/prt0992_13_05_2009.html. Acesso em: 17 fev. 2022.

Práxis Educativa, Ponta Grossa, v. 17, e2219336, p. 1-10, 2022 Disponível em: < https:// revistas2.uepg.br/index.php/praxiseducativa $>$ 
BRASIL. Glossário temático: gestão do trabalho e da educação na saúde. 2. ed. Brasília: Ministério da Saúde, Secretaria-Executiva, Secretaria de Gestão do Trabalho e da Educação na Saúde, 2012. Disponível

https://bvsms.saude.gov.br/bvs/publicacoes/glossario_gestao_trabalho_2ed.pdf. Acesso em: 17 fev. 2022.

BRASIL. Temático Saúde da População. Brasília: Ministério da Saúde, Secretaria de Gestão Estratégica e Participativa, Departamento de Articulação Interfederativa, 2016. Disponível em: https://bvsms.saude.gov.br/bvs/publicacoes/tematico_saude_populacao_negra_v._7.pdf.

Acesso em: 17 fev. 2022.

BRASIL. Política Nacional de Saúde Integral da População Negra: uma política para o SUS. 3. ed. Brasília: Ministério da Saúde, 2017. Disponível em: https://bvsms.saude.gov.br/bvs/publicacoes/politica_nacional_saude_populacao_negra_3d.pdf. Acesso em: 17 fev. 2022.

CANAVESE, D. et al. Equidade étnicorracial no SUS: pesquisas, reflexões e ações em saúde da população negra e dos povos indígenas. Porto Alegre: Rede UNIDA, 2018. (Série Atenção Básica e Educação na Saúde, v. 15).

CASARIN, M. R.; PICOLLI, J. C. E. Educação em saúde para prevenção do câncer de colo do útero em mulheres do Município de Santo Ângelo/RS. Ciência \& Saúde Coletiva, Rio de Janeiro, v. 16, n. 9, p. 3925-3932, set. 2011. DOI: https://doi.org/10.1590/S1413-81232011001000029

DESCRITORES EM CIÊNCIAS DA SAÚDE. DeCS/MeSH. 2020. Disponível em: https://decs.bvsalud.org/. Acesso em: 17 fev. 2022.

DIAS, V. P.; SILVEIRA, D. T.; WITT, R. R. Educação em Saúde: O trabalho de grupos em atenção primária. Revista de APS, Juiz de Fora, v. 12, n. 2, p. 221-227, abr./jun. 2009.

FERREIRA, J. A. Constituição de uma política de saúde para a população negra no Sistema de Saúde brasileiro. Contraponto, Porto Alegre, v. 4, n. 2, p. 103-122, 2017.

GOMES, N. L. Diversidade étnico-racial, inclusão e equidade na Educação Brasileira: desafios, políticas e práticas. Revista Brasileira de Política e Administração da Educação, Brasília, v. 27, n. 1, p. 109-121, jan./abr. 2011. DOI: https://doi.org/10.21573/vol27n12011.19971

GONDRA, J. G. A Sementeira do Provir: higiene e infância no século XIX. Educação e Pesquisa, São Paulo, v. 26, n. 1, p. 99-117, jan./jun. 2000. DOI: https://doi.org/10.1590/S1517$\underline{97022000000100008}$

HONE, T. et al. Association between expansion of primary healthcare and racial inequalities in mortality amenable to primary care in Brazil: a national longitudinal analysis, São Francisco, v. 14, n. 5, e1002306, maio 2017. DOI: https://doi.org/10.1371/journal.pmed.1002306

IBGE. Instituto Brasileiro de Geografia e Estatística. Censo Demográfico 2010. Disponível em: https://censo2010.ibge.gov.br/resultados.html. Acesso em: 10 jan. 2022.

KALCKMANN, S. et al. Racismo Institucional: um desafio para a equidade no SUS? Saúde e Sociedade, São Paulo, v. 16, n. 2, p. 146-155, ago. 2007. DOI: https://doi.org/10.1590/S0104$\underline{12902007000200014}$

MATOS, C. C. S. A.; TOURINHO, F. S. V. Saúde da População Negra: percepção de residentes e preceptores de Saúde da Família e Medicina de Família e Comunidade. Revista Brasileira de 
Medicina de Família e Comunidade, Rio de Janeiro, v. 13, n. 40, p. 1-12, jun. 2018. DOI: https://doi.org/10.5712/rbmfc13(40)1712

SAMPAIO, E. de O. Racismo Institucional: desenvolvimento social e políticas públicas de caráter afirmativo no Brasil. Revista Internacional de Desenvolvimento Local, Campo Grande, v. 4, n. 6, p. 77-83, mar. 2003.

SEN, A. Por qué la equidade en salud? Revista Panamericana de Salud Publica, Washington, v. 11, n. 5-6, p. 302-309, 2002. DOI: https://doi.org/10.1590/S1020-49892002000500005

SILVA, J. R. A. et al. Educação em Saúde na Estratégia de Saúde da Família: percepção dos profissionais. Revista Brasileira de Promoção à Saúde, Fortaleza, v. 28, n. 1, p. 75-81, jan./mar. 2015. DOI: https://doi.org/10.5020/18061230.2015.p75

VASCONCELOS, E. M. Participação popular e educação nos primórdios da saúde pública brasileira. A saúde nas palavras e nos gestos: reflexões da Rede de Educação Popular nos Serviços de Saúde. São Paulo: Hucitec, 2001.

Recebido em 07/08/2021

Versão corrigida recebida em 08/02/2022

Aceito em 11/02/2022

Publicado online em 22/02/2022

Práxis Educativa, Ponta Grossa, v. 17, e2219336, p. 1-10, 2022 